\title{
Evaluation of the Marginal Location and Periodontal Health in Crowns and Bridges - A Patient Preference Based Study
}

\author{
Misha Salim ${ }^{1}$ \\ Rija Tirmizi ${ }^{2}$ \\ Maria Shakoor Abbasi ${ }^{3}$ \\ Naseer Ahmed ${ }^{4}$ \\ Muneeb Ahmed Lone ${ }^{5}$ \\ Haroon Rashid ${ }^{6}$ \\ Rizwan Jouhar ${ }^{7}$
}

\author{
BDS \\ BDS \\ BDS, FCPS \\ BDS, FCPS \\ BDS, FCPS \\ BDS, MDSC \\ BDS, FCPS
}

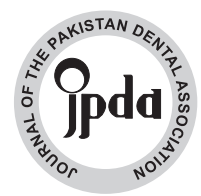

OBJECTIVE: The objective of this paper was to evaluate the marginal location preference and periodontal health in extra coronal restoration of anterior and posterior teeth.

METHODOLOGY: In this prospective case control study, a total of 652 patients who had crown and bridge for not less than six months were included. The gingival margin location preference and reasons behind choosing a particular gingival margin was asked from the patients. Additionally, the teeth with and without restoration were also examined for periodontal health. Split mouth technique was used as unrestored, healthy contra lateral teeth in the same individual served as controls. Descriptive statistics and Chi square test were used for analysis to formulate the results.

RESULTS: Ironically, 92\% patients were not given a chance by their dentist to give input about margin location preference. The majority of patients preferred equi gingival margin for their anterior crowns 495 (75.92\%) and supra gingival margin 586 $(89.87 \%)$ for their posterior teeth, with esthetics 547 (83.89\%) and hygiene $599(91.87 \%)$ respectively being the most common reasons for selecting the particular margin location. The clinical examination revealed that supra gingival and equi gingival margins demonstrated superior gingival health indices as compared to subgingival margins

CONCLUSION: This study concluded that the supra gingival and equi gingival margins demonstrated superior gingival health indices as compared to subgingival margin and in order to achieve optimal periodontal health and patient satisfaction the health professionals should wisely consider the margin location and involve the patient in treatment decisions wherever possible. KEY WORDS: Crown and Bridge, Margin location, Patient preference, Periodontal Health.

HOW TO CITE: Salim M, Tirmizi R, Abbasi MS, Ahmed N, Lone MA, Rashid H, Jouhar R. Evaluation of the marginal location and periodontal health in crowns and bridges - A patient preference based Study. J Pak Dent Assoc 2021;30(3):194-198. DOI: https://doi.org/10.25301/JPDA.303.194

Received: 18 July 2020, Accepted: 02 April 2021

\section{INTRODUCTION}

$\mathrm{T}$ he orodental function, aesthetics and phonetics are the premium ultimate goal of all prosthetic treatment. ${ }^{1}$ Optimal soft and hard tissues health following

1. House surgeon, Department of Prosthodontics, Altamash Institute of Dental Medicine, Karachi, Pakistan.

2. House surgeon, Department of Prosthodontics, Altamash Institute of Dental Medicine, Karachi, Pakistan.

3. Assistant Professor, Department of Prosthodontics, Altamash Institute of Dental Medicine, Karachi, Pakistan.

4. Associate Professor, Department of Prosthodontics, Altamash Institute of Dental Medicine, Karachi, Pakistan.

5. Assistant Professor, Department of Prosthodontics, Dr Ishrat-ul-Ebad Institute of Oral Health Sciences Dow University of Health Sciences, Karachi.

6. Associate Professor, Department of Prosthodontics, Ziauddin University, Karachi, Pakistan.

7. Associate Professor, Department of Operative dentistry, Altamash Institute of Dental Medicine, Karachi, Pakistan.

Corresponding author: "Dr. Naseer Ahmed" < naprosthodontist@ gmail.com > prosthetic treatment is a pre requisite for improvement in longevity. ${ }^{2}$

Periodontium is considered as the prime determinant to achieve a satisfactory outcome based on adequate function, esthetics and comfort. ${ }^{3}$ The interplay between periodontology and restorative dentistry is present at many fronts, including location of restorative margins, crown contours, and response of the gingival tissues to restorative preparations. ${ }^{4}$

The detrimental effects of management may occur in restorative rehabilitation, majorly due to inadequate teeth preparation, choosing inappropriate margin geometry and location. ${ }^{5}$ There are different types of margin geometry and locations to be followed based on location of teeth, teeth height, crown root ratio, vitality of the teeth, amount of remaining tooth substance and aesthetic requirements. ${ }^{6}$

From the past many decades in restorative dentistry, the 
Salim M/ Tirmizi R/ Abbasi MS/ Ahmed N/ Lone MA/ Rashid H/ Jouhar R

location of gingival finish line due to its relation to the periodontium is under considerable debate for a best possible consensus. ${ }^{7}$ Investigators have repeatedly demonstrated that subgingival margins produced gingival inflammation indicated by an elevated gingival index (GI), increased plaque index (PI), and increased pocket depths (PD). ${ }^{8,9}$ Moreover, some studies on the contrary revealed that margin placement had only limited effect on the periodontal indices. ${ }^{10-12}$

The margin in full coverage restoration is critical for periodontal health therefore precision need to be adopted in its geometry and location. Additionally, patient choice should be taken in consideration as part of treatment success; opting a subgingival location to achieve optimal aesthetics in every case is injustice that can be avoided by discussion and education by the clinician. The gingival health can be jeopardize by the crown and bridge margins as described by Gunay et al in a prospective 2-year clinical trial, in which papillary bleeding index (PBI) was analyzed before, and 3, 6, 12 and 24 months after crown therapy on 116 teeth. ${ }^{11}$ Therefore, the purpose of this study was to analyze periodontal health, patient preference and reason for selecting location of margins in single crown and bridges.

\section{METHODOLOGY}

This prospective case control study was conducted at the department of prosthodontics Altamash Institute of Dental Medicine. The study was approved by ethics and review committee of AIDM/EC/11/2019/19. A well-structured questionnaire consisted of two sections with closed ended questions was used to collect the information from participants. Section one comprised of demographic details of participants while section two was focused on gingival margin location preference and reasons behind choosing a particular gingival margin. Random sampling technique was used to recruit participants. A total of 702 patients participated in the study. On scrutiny 50 partially filled or duplicate forms were excluded. The final number of participants included in the study was 652 . The objective, consent statement for voluntary participations and declarations of anonymity and confidentiality was included in the questionnaire for all subjects to understand prior to their agreement and then a clinical evaluation was performed. Patients were selected according to the following inclusion and exclusion criteria:

\section{Inclusion Criteria}

- Both Gender

- Patients age 20-50 years

- Vital and non-vital teeth treated with Crown or Fixed dental prosthesis more than 6 months back
Marginal location preference and periodontal health in crowns and bridges

- Healthy patients without any systemic disease or co morbids

- Non Smoker

- With no known allergies

- No active parafunctional habits

\section{Exclusion Criteria}

- Patients without crown and bridge work after root canal treatment.

- Evidence of generalized periodontal problems

- Mentally unstable

- Non-compliant patients

After the selection of the patients according to the above mentioned criteria, the patients were given a chance to express their opinion of how they wanted their crown and bridge marginal location to be, which was never considered previously as they had rarely been given the option for it. Patients were educated about the pros and cons of specific marginal location and were shown pictures of crowns/bridges and asked what they preferred in the anterior teeth or posterior teeth and what their reasons were. Patients were also asked if they had been asked for their preference initially and if yes, were they satisfied or any pictures were shown of supra gingival, equi gingival and subgingival crowns before asking for their opinion.

Moreover, the gingival health of teeth with and without restoration was checked for pocket depth, marginal fit and presence of positive and negative ledge, plaque index and signs of bleeding as described by Silness $\mathrm{P}$ and Loe $\mathrm{H}^{8}$ in 1964. Split mouth technique was used as unrestored, healthy contra lateral teeth in the same individual served as controls. The examination was carried out with sickle probe and periodontal probe.

The data were finally entered in SPSS-25 for statistical analysis, Descriptive statistics were carried out to obtain frequency, mean values, standard deviation and percentages. Chi Square test was used to analyze the effect of gender on marginal preference and association between reason of margin preference in anterior and posterior teeth. A p value of $(\leq 0.05)$ was considered as statistically significant.

\section{RESULTS}

In this study, out of 702 participants, 652 were included with a response rate of $92.87 \% .302(46.31 \%)$ were males and $350(53.68 \%)$ females. The mean age of participants was $45.48 \pm 15.03$. The (Figure-1) is illustrating that majority of patients preferred equi gingival margin for their anterior crowns 495 (75.92\%), followed by supra gingival margin $131(20.09 \%)$ and subgingival margin 26 (3.99\%) 
Salim M/ Tirmizi R/ Abbasi MS/ Ahmed N/ Lone MA/ Rashid H/ Jouhar R

respectively. On the other hand. (Figure-2) revealed patient preference over posterior crown margin, that is, supra gingival

Figure 1: Gingival Margin Preference in Anterior teeth $n=652$

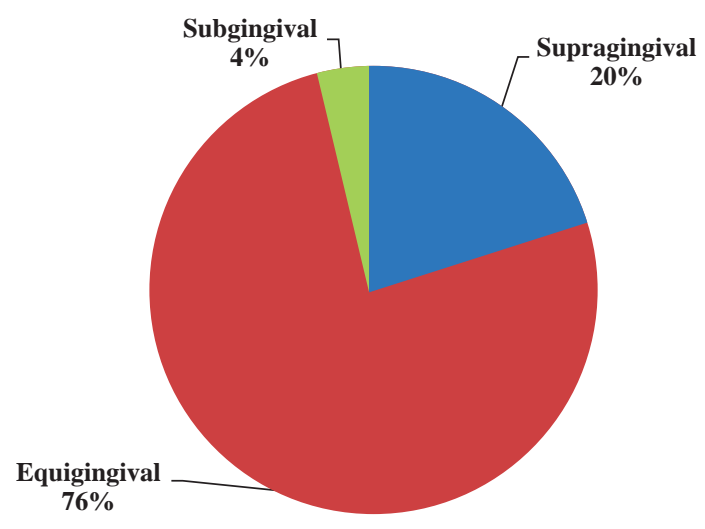

Figure 2: Gingival margin preference in posterior teeth $n=652$

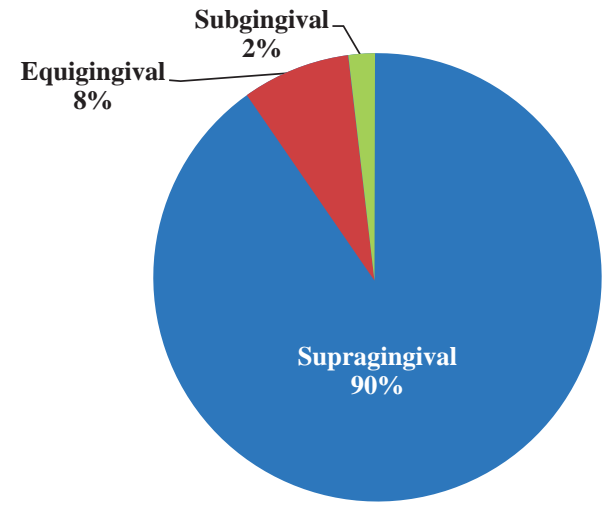

margin $586(89.87 \%)$ equi gingival $53(8.12 \%)$, and subgingival 13 (3.98\%).

The reasons for opting a certain crown margin for their anterior teeth is described in (Table-I) Esthetics was the main reason for selection of equi gingival margin 547 (83.89\%), followed by $65(9.96 \%)$ participants who thought that it was easier to maintain hygiene with equi gingival margin while $22(3.37 \%)$ participants opted it for others reasons. A mere $18(2.76 \%)$ participants felt that it will provide better mastication. The reason for preference of supra gingival crown margin in posteriors was majorly hygiene and maintenance, 599 (91.87\%) followed by others "durability" $26(3.98 \%)$ and esthetics was chosen by 19 (2.91\%). There was a significant difference $(\mathrm{p}=0.013)$ between reasons of choosing a particular marginal location amongst the participants as described in (Table I). Similarly, when marginal location preference was compared with gender a significant difference $(\mathrm{p}=0.001)$ was revealed as presented in (Table II).
Marginal location preference and periodontal health in crowns and bridges

Table 1: Reasons for preference of gingival margin location in teeth $\mathrm{n}=652$

\begin{tabular}{|c|c|c|c|c|c|}
\hline & $\begin{array}{c}\text { Aesthetics } \\
\text { n \% }\end{array}$ & $\begin{array}{c}\text { Hygiene } \\
\text { n \% }\end{array}$ & $\begin{array}{c}\text { Mastication } \\
\mathbf{n} \%\end{array}$ & $\begin{array}{c}\text { Others } \\
\mathrm{n} \%\end{array}$ & P value \\
\hline Anterior teeth & $547(83.89 \%)$ & $65(9.96 \%)$ & $18(2.76 \%)$ & $22(3.37 \%)$ & \multirow[t]{2}{*}{0.013} \\
\hline Posterior teeth & $19(2.91 \%)$ & $599(91.87 \%)$ & $8(1.22 \%)$ & $26(3.98 \%)$ & \\
\hline
\end{tabular}

Table 2: Gender based distribution of margin location preference $n=652$

\begin{tabular}{|c|c|c|c|}
\hline Anterior teeth & Male n\% & Female n\% & P value \\
\hline Supragingival & $72(11.04)$ & $59(9.04)$ & \multirow{7}{*}{0.001} \\
\hline Equigingival & $220(33.74)$ & 275 (42.17) & \\
\hline Subgingival & $10(1.53)$ & $16(2.45)$ & \\
\hline Posterior teeth & & & \\
\hline Supragingival & $273(41.87)$ & $313(48.00)$ & \\
\hline Equigingival & $21(3.22)$ & $32(4.90)$ & \\
\hline Subgingival & $8(1.22)$ & $5(0.76)$ & \\
\hline
\end{tabular}

In our study the type of crown and bridge in use by the patients was mostly porcelain fused to metal (PFM) 488 (74.84\%), all ceramic 114 (17.48\%) whereas only $50(7.66 \%)$ metal crowns. Patients were interviewed if they had been ever asked for their preference initially in past to which we got a negative response from 601 (92.17\%) participants while $51(7.82 \%)$ opted that they were asked about margin location preference by the respective dentist. Additionally, the existing gingival margins in anterior and posterior teeth of participants was located sub gingival in majority 591(90.64\%) of the patients. This basically shows how little information and input they had regarding their restoration during the course of treatment. Moreover, the clinical examination of restored and control teeth revealed that supra gingival and equi gingival margins demonstrated superior gingival health indices compared to subgingival margins. Gingival index scores were in the category of mild to moderate gingivitis: 0.1 to 2.0 in subgingival margins while in supra gingival margins the score for plaque index falls in excellent $=0$ and no signs of bleeding were evident wit requisite adequate oral hygiene.

\section{DISCUSSION}

The selection of crown margin plays a vital role as it is directly related with periodontal tissue. ${ }^{13}$ Aesthetics is an integral outcome of dental restoration which along with gingival margin placement, gingival pigmentation, gingival biotype depends on multiple other factors. ${ }^{14}$ More than thirty-five years ago Amsterdam wrote about periodontal prosthesis, he described the optimal margin/finish line 
Salim M/ Tirmizi R/ Abbasi MS/ Ahmed N/ Lone MA/ Rashid H/ Jouhar R

which should be placed in a healthy sulcus at a minimal depth, just short of the junctional epithelium. ${ }^{15}$ Our study revealed that crowns with supra gingival preparations demonstrated superior gingival health indices with an added advantage of less gingival tissues irritation by excess cements compared to subgingival preparations, which is in accordance with findings of Jagathpal et al who revealed a significant difference between ginigival health and different techniques used in crown luting. ${ }^{16}$

In our study the gingival health in restored teeth were adequate with supragigival, equigingival margins, adequate oral hygiene and with appropriate fitted crown and bridges. Similarly, Atlas et al reported that marginal fit of crown is consider more significant in reference to inflammation then crown length. ${ }^{17}$ Moreover, other factors also contribute to poor periodontal health around crowns, such as open and over-hanging margins, irregular surface texture and improper emergence profile due to over-contoured morphology. ${ }^{18}$ Therefore, consideration should be given to precise planning of gingival margins because the gingival inflammation around margins can be avoided by following proper oral hygiene regime. ${ }^{19}$

Our study revealed that subgingival margins were least preferred in both anterior and posterior teeth. Although subgingival margins are important when aesthetics is concern. On the other hand, it significantly increases the incidence of periodontal disease, surface roughness, marginal fit and crown contour, reconcile plaque accumulation and persuade gingival health. Especially in posterior teeth crowns where spontaneous bleeding was greater with the placement of sub-gingival crown. These findings are similar and supported by Sorensen et al. ${ }^{20}$

In our study, Equigingival margins were preferred by majority of participants as far as anterior teeth were concerned. The main reason for this selection was aesthetics. While supra gingival margins was opted the best alternative in posterior teeth, the reason of preference was maintenance and hygiene, adequate gingival health and absence of spontaneous bleeding. Moreover, traditionally equi gingival margins were not recommended because it was believed that they retain more plaque as a result cause more inflammation than supra gingival or subgingival margins. But in today's world it is proven that periodontally both equigingival and supragingival margins are well tolerated. ${ }^{21}$ Therefore, we believed that restoring a tooth with healthy and compromised periodontal health with an appropriate full-coverage restoration, along with gingival margin location and geometry using modern materials that are presented to reduce the risk of additional plaque retention should be considered the treatment of choice for maintaining prolonged dental health.
Marginal location preference and periodontal health in crowns and bridges

\section{CONCLUSION}

This study concluded that the supra gingival and equi gingival margins demonstrated superior gingival health indices as compared to subgingival margin and in order to achieve optimal periodontal health and patient satisfaction the health professionals should wisely consider the margin location and involve the patient in treatment decisions wherever possible.

\section{ACKNOWLEDGEMENT}

The authors are grateful to Research Ethics and Review Committee of Altamash Institute of Dental Medicine. Also, to Dow University of Health Sciences and Ziauddin University for facilitation and support in this study.

\section{CONFLICT OF INTEREST}

The authors declared no conflict of interest.

\section{FUNDING}

No company or institution financially contributed to this study.

\section{REFERENCES}

1. Ahmed N, Faruqui S. Factors affecting dental prosthesis satisfaction in Pakistani population. Internet J Dent Res. 2015;3:24-26.

https://doi.org/10.14419/ijdr.v3i2.5439

2. Ahmed N, Abbasi MS, Alavi FB, Naz A, Masood S, Irfan AB. Factors influencing the treatment options for single missing tooth: A patient preference based study. Isra Med J. 2021;13:24-8

3. Konstantinidis, I.; Trikka, D.; Gasparatos, S.; Mitsias, M.E. Clinical Outcomes of Monolithic Zirconia Crowns with CAD/CAM Technology. A 1-Year Follow-Up Prospective Clinical Study of 65 Patients. Int. J. Environ. Res. Public Health 2018;15:2523 (1-11).

https://doi.org/10.3390/ijerph15112523

4. Nemcovsky, C.E.; Beitlitum, I. Combination Therapy for Reconstructive Periodontal Treatment in the Lower Anterior Area: Clinical Evaluation of a Case Series. Dent. J. 2018;6;50 (1-12). https://doi.org/10.3390/dj6040050

5. Hadyaoui, D.; Daouahi, N.; Nouira, Z.; Cherif, M. Gingival Harmony in Anterior Aesthetic Restorations. Dent. J. 2014;2:155-62. https://doi.org/10.3390/dj2040155

6. Shankar S, Gounder R, Ganapathy D. Standards of teeth preparation for anterior all-ceramic crowns in private dental practice. Drug Invention Today. 2020;14:484-87.

https://doi.org/10.5958/0974-360X.2020.00207.3 


\section{Salim M/ Tirmizi R/ Abbasi MS/ Ahmed N/ Lone MA/ Rashid H/ Jouhar R}

7. Silness J. Periodontal conditions in patients treated with dental bridges: the relationship between the pontic and the periodontal condition of the abutment teeth. J Periodont Res 1974; 9:50-5. https://doi.org/10.1111/j.1600-0765.1974.tb00653.x

8. Silness J, Löe H. Periodontal disease in pregnancy II. Correlation between oral hygiene and periodontal condition. Acta odontologica scandinavica. 1964:1;22:121-35.

https://doi.org/10.3109/00016356408993968

9. Silness J, Ohm E. Periodontal conditions in patients treated with dental bridges: V. Effects of splinting adjacent abutment teeth. J Periodont Res 1974; 9:121-6.

https://doi.org/10.1111/j.1600-0765.1974.tb00663.x

10. Janenko C. Anterior crowns and gingival health. Aust Dent J 1979; 24:225-30.

https://doi.org/10.1111/j.1834-7819.1979.tb02929.x

11. Gunay H, Seeger A, Tschernitschek H, Geurtsen W. Placement of the preparation line and periodontal health--a prospective 2-year clinical study. Int J Periodont Rest Dent. 2000:1;20:1 $73-81$.

12. Sheehan SA, Alqahtani HM, Ahmed N. Assessment of staff perspective toward restored endodontically treated teeth at selected dental clinics, in Saudi Arabia. J Int Oral Health 2018; 10:32-5.

13. Younus Z, Maniya Z, Ahmed N, Faruqui S, Jouhar R, Maqsood A, Bukhsh HA. Periodontal health of natural abutments in removable partial denture wearers. Pak Oral Dental J. 2017; 37, 175-78.

14. Ghani B, Jouhar R, Ahmed N. Relationship of Facial Skin Complexion with Gingiva and Tooth Shade on Smile Attractiveness.
Marginal location preference and periodontal health in crowns and bridges

J Interdiscipl Med Dent Sci. 2016;4(205):2.

https://doi.org/10.4172/2376-032X.1000205

15. Amsterdam M. Periodontal prosthesis. Twenty-five years in retrospect. The Alpha Omegan. 1974;67:8-52.

16. Jagathpal AJ, Vally ZI, Sykes LM, du Toit J. Comparison of excess cement around implant crown margins by using 3 extraoral cementation techniques. J Prosthet Dent. 2021;26:95-101.

https://doi.org/10.1016/j.prosdent.2020.04.01

17. Atlas A, Isleem W, Bergler M, Fraiman HP, Walter R, Lawson ND. Factors Affecting the Marginal Fit of CAD-CAM Restorations and Concepts to Improve Outcomes. Current Oral Health Reports. 2019;6:277-83.

https://doi.org/10.1007/s40496-019-00245-2

18. Valderhaug J, Birkeland JM. Periodontal conditions in patients 5 years following insertion of fixed prostheses. J Oral Rehabil;237-43. https://doi.org/10.1111/j.1365-2842.1976.tb00949.x

19. Valderhaug J, Heloe LA, Oral hygiene in a group of supervised patients with fixed prostheses. J Periodontol 1977; 48:221-24. https://doi.org/10.1902/jop.1977.48.4.221

20. Sorensen SE, Larsen I, Jorgensen KD. Gingival and alveolar bone reaction to marginal fit of subgingival crown margins. Eur J Oral Sci. 1986:1;94:109-14

https://doi.org/10.1111/j.1600-0722.1986.tb01373.x

21. Razi M, Debnath S, Chandra S, Hazra A. Biologic WidthConsidering Periodontium in Restorative Dentistry. Int J Contemp Med Res.. 2019;6:5-11.

https://doi.org/10.21276/ijcmr.2019.6.3.15 